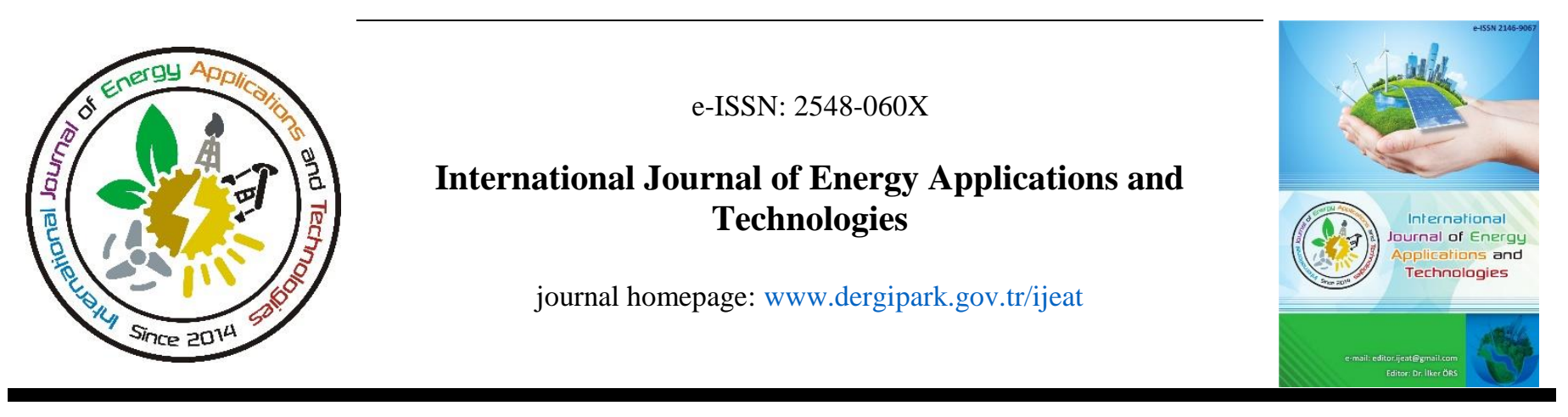

Original Research Article

\title{
Estimation of li-ion battery state of charge using adaptive neural fuzzy inference system (ANFIS)
}

\author{
Yusuf Karabacak $^{1}$, İlker Ali Özkan ${ }^{2 *}$, İsmail Sarıtaş ${ }^{3}$ \\ ${ }^{I}$ Land Forces NCO Vocational School, Turkish National University, Balıkesir, Turkey \\ ${ }^{2}$ Computer Engineering Department, Faculty of Technology, Selcuk University, Konya Turkey \\ ${ }^{3}$ Electrical and Electronics Engineering Department, Faculty of Technology, Selcuk University, Konya Turkey
}

\section{ARTICLE INFO \\ * Corresponding author ilkerozkan@selcuk.edu.tr \\ Received August 10, 2020 \\ Accepted September 29, 2020 \\ Published by Editorial Board Members of IJEAT \\ (C) This article is distributed by Turk Journal Park System under the CC 4.0 terms and conditions.}

doi: 10.31593/ijeat.778689

\begin{abstract}
Thanks to their electrochemical structure, batteries are the elements that can store electrical energy and spend on a load when the electrical energy they store is needed. Today, with the widespread use of electrically powered mobile devices, rechargeable batteries have become widespread and battery technologies have developed. With the idea that the latest technology systems and electric vehicles will become widespread in the future, the studies on batteries are increasing day by day. In this study, charge state estimation of Li-ion battery cell used to provide power in many applications was realized by using adaptive neural fuzzy inference system (ANFIS). A Li-ion battery was discharged using variable electrical loads with a battery discharge circuit modeled on MATLAB Simulink and current, voltage, temperature and current power parameters of the battery were selected as input variables. Battery parameters and charge status data obtained from discharge tests using different electrical loads on MATLAB Simulink were used as training and test parameters of neural network. Using the MATLAB ANFIS toolbox, the system was trained with $80 \%$ of the battery parameters obtained in the battery discharge experiments and with $20 \%$ as testing data, the success performance was interpreted by applying the adaptive neural fuzzy inference system.
\end{abstract}

\section{Introduction}

The batteries have a wide range of applications. Portable electronic devices, commercial and industrial applications, the automobile industry, power systems that intervene when main power fails, and satellites are some of the fields which have use of batteries. There are many types of batteries depending on the area in which they are used. The manufacturers make battery selection considering energy capacity, weight, number of cycles and size.

Batteries are complex systems that are not linear due to their chemical structure. Chemical, mathematical and electrical methods are used to model the batteries. A highly accurate, intuitive and comprehensive electrical battery model can be developed in the computer environment. In this type of modeling, all the dynamic characteristics of the battery can be calculated which are the non-linear parameters such as open circuit voltage, current, temperature, number of pulses, capacity-dependent storage time [1]. In order to estimate the current-voltage behavior of the batteries, there are simulation models using the MATLAB curve fitting toolbox by combining the electrical circuit model with the RC circuit [2]. The battery equivalent circuit model can be realized in MATLAB / Simulink environment so that the space state equations of the battery can be obtained by using the differential equations which calculate the dynamic parameters of the battery [3]. By using the electrical model of batteries, energy saving can be achieved by performing 
energy management system algorithms in electric vehicle systems used under variable loads [4].

Batteries are equipment that make our lives easier. By using the batteries correctly, it is possible to extend the service life. In order to use the batteries efficiently, they should not be used outside the limit values. Operating outside the operating temperatures, taking more current from the battery, overcharging or over-discharging are some of the factors that reduce the life of the battery. Such problems are prevented by battery management systems (BMS) [5]. The voltage of the battery cells is monitored by the BMS and the cells are compensated. Voltage, internal resistance, current of each cell can be monitored [6]. As a result of studies in the literature, it was stated that BMS improves the management of independent battery arrays. [7]. The algorithm for operating the BMS should be the weakest cell based. Singlecell BMS provides the user with information on temperature and voltage and helps prevent over-discharge [8]. It is important to obtain high efficiency from the battery under different operating conditions. The BMS plays an important role in the optimization of the charge and discharge mechanism control of the battery as well as in indicating the status of the battery [9]. Li-Ion batteries require an BMS to ensure maximum performance and safety. [10]. Intelligent developed for Li-Ion batteries used in electric vehicles provides information about the instantaneous state of the battery. [11]. For the Li-Ion battery pack used in electric vehicles, the charge status estimation was performed with an artificial neural network algorithm [12]. In different methanol mixtures for an internal combustion engine, the effect on engine emissions and performance is estimated using an ANFIS model [13]. Li-ion batteries are used in electric vehicles [14-15].

Efficient use of storable energy resources, which are becoming more and more needed today, is of great importance. Excess chemical substances in its structure cause serious harm to both human health and nature. However, it is possible to make these energy sources last longer thanks to the correct usage methods. In this respect, it is foreseen to minimize the harm to human health and environment. In this study, the state of charge of Li-Ion battery is estimated with ANFIS application, which is one of the hybrid artificial intelligence techniques. By determining the state of charge of the battery, it is aimed to determine the most suitable working area and use it more efficiently.

\section{Li-Ion Battery}

Today, Li-Ion batteries are the most preferred type of battery in most of the portable hand tools from mobile phones to laptops. Figure 1 shows the image of this battery. Li-Ion batteries have a wide operating temperature range since they can be used between $-20^{\circ} \mathrm{C}$ and $+60^{\circ} \mathrm{C}$ during charging and between $-40^{\circ} \mathrm{C}$ and $+65^{\circ} \mathrm{C}$ during discharge. Li-Ion battery cell voltages are between $2.5 \mathrm{~V}$ and $4.2 \mathrm{~V}$ and are approximately three times that of other battery types [16-18].

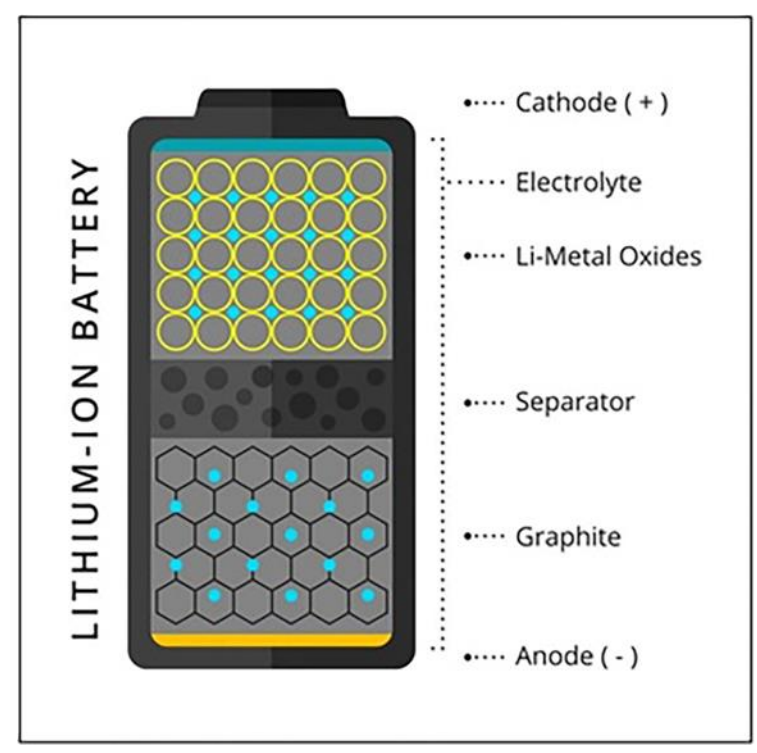

Fig. 1. Lithium-Ion Battery [19]

\subsection{Mathematical modeling of the battery}

With the mathematical model of the batteries, it is possible to calculate the open circuit voltage and charge status parameters of the battery. One of the most basic mathematical equations used in the calculation of battery charge status is the Peukert equation. The Peukert rule was published in 1897 by the German scientist W. Peukert. With this rule, the capacity of the lead acid battery is calculated according to the discharge rate [19].

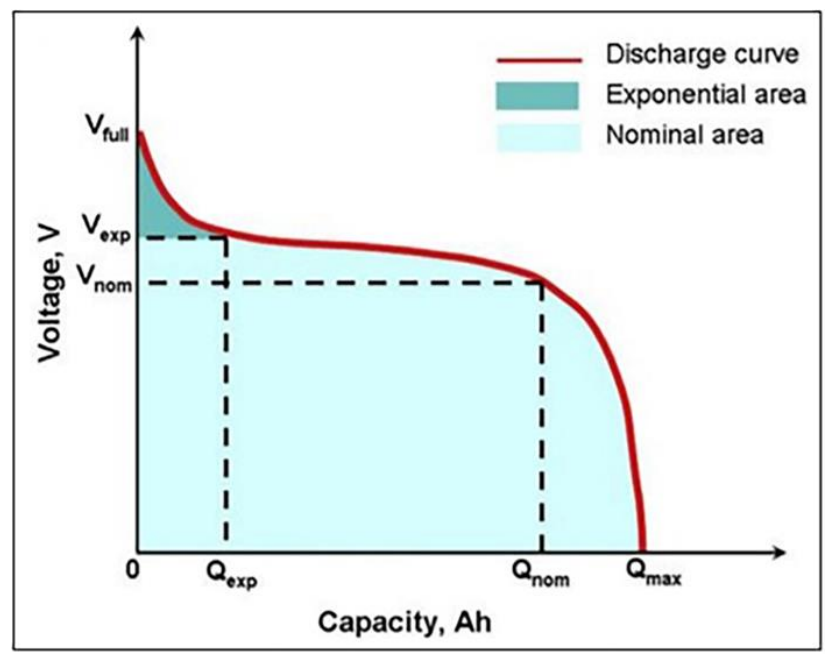

Fig. 2. Typical discharge curve [20]

As can be seen from the battery discharge curve given in Figure 2, the usable capacity of the battery decreases as the discharge rate increases. The Peukert rule for one-ampere discharge rate is expressed as in Equation 1.

$$
C_{p}=I^{k} t
$$

Here $\mathrm{Cp}$ is the capacity at the discharge rate of one-ampere and expressed in $\mathrm{Ah}, \mathrm{I}$ is the current value drawn by the load, 
$\mathrm{t}$ is the time in hours. Usually the discharge rate of the battery cells is not $1 \mathrm{Ah}$. When the formula is rearranged according to the capacity and discharge rate, it is as in Equation 2.

$$
t=H\left(\frac{C}{I H}\right)^{k}
$$

In Equation 2, the nominal discharge time in hours $\mathrm{H}$, nominal capacity in $\mathrm{Ah}$ in discharge rate $\mathrm{C}$, the measured discharge current in I A, $\mathrm{k}$ Peukert constant, $\mathrm{t}$ is the time elapsed when discharging the battery in hours. [21].

Tremblay and Dessaint mathematically expressed the charge and discharge dynamics of rechargeable batteries. Figure 2 shows a typical discharge curve for a NiMH battery cell. The most important feature of this model is that the filtered current $\left(\mathrm{i}^{*}\right)$ through the polarization resistance is used. With this parameter, algebraic problems in simulation are overcome.

$$
V_{b}=E_{0}-\underbrace{K \frac{Q}{Q-i t}}_{\begin{array}{c}
\text { Polarization } \\
\text { voltage }
\end{array}} \cdot i t-R_{i c} \cdot i+\operatorname{GExp}(B \cdot i t)-\underbrace{K \frac{Q}{Q-i t}}_{\begin{array}{c}
\text { Polarization } \\
\text { resistance }
\end{array}} \cdot i
$$

In Equation 3, $\mathrm{Vb}$ is the battery voltage (V), E0 is the battery constant voltage $(\mathrm{V}), \mathrm{K}$ is the polarization constant (V/ Ah) or the polarization resistance $(\Omega), \mathrm{Q}$ is the battery capacity (Ah), it is the actual battery charge (Ah) $\mathrm{G}$ is the exponential zone amplitude (V), B is the exponential zone time constant inverse $(\mathrm{Ah})-1$, Ric is the internal resistance $(\Omega), \mathrm{i}$ is the battery current (A) and $i^{*}$ is the filtered current (A). The exponential area given in Equation 3 applies to Li-Ion batteries. However, for other batteries, there is a case of hysteresis where the charge state of the battery is not important between charge and discharge. This occurs in the exponential area given in Figure 2. This phenomenon can be expressed in a nonlinear dynamic system as given in Equation 4.

$$
\operatorname{Exp}(t)=B \cdot|i(t)| \cdot(\operatorname{Exp}(t)+A \cdot u(t))
$$

In Equation 4, $\operatorname{Exp}(\mathrm{t})$ is the exponential field voltage, $\mathrm{i}(\mathrm{t})$ is the battery current, $u(t)$ is the charge or discharge mode $(u(t)$ $=1$ charge, $\mathrm{u}(\mathrm{t})=0$ discharge $)$. Figure 2 shows the entire discharge pattern.

The charging pattern of the battery varies depending on the battery type. The charge end characteristics of $\mathrm{Pb}, \mathrm{Li}$-ion, Lipo batteries are similar. Because the voltage rises rapidly when the battery approaches the full charge. This phenomenon is modeled by polarization resistance. In charging mode, the polarization resistance increases until the battery is almost fully charged. Above this point, the polarization resistance suddenly increases. The polarization resistance during discharge is now $\mathrm{K} \cdot \mathrm{Q} / \mathrm{it}$. Theoretically, when the charge current is equal to zero, the polarization resistance is infinite. But in practice this is not the case. Figure 3 shows the electrical discharge circuit of a battery. According to the data obtained from experimental studies, the battery capacity varies by $10 \%$. The polarization resistance is therefore expressed as given in Equation 5. Like the discharge model, the exponential field is similar for LiIon, LiPo and $\mathrm{Pb}$ batteries.

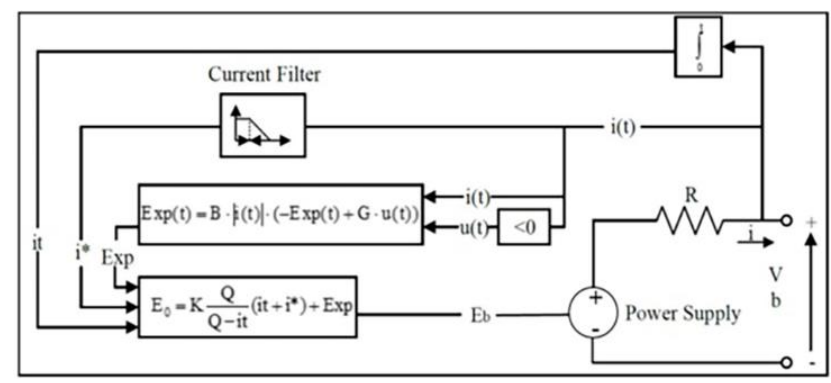

Fig. 3. Battery discharge model

$$
\text { Pol.resistance }=K \frac{Q}{i t-0.1 \cdot Q}
$$

The charging end characteristics of $\mathrm{NiMH}$ and $\mathrm{NiCd}$ batteries are different. When the battery reaches full charge voltage, the voltage decreases slowly depending on the current amplitude. This phenomenon can be modeled by changing the polarization resistance. When the battery is fully charged (it $=0$ ), the voltage begins to drop. The charger tries to overcharge the battery (it $<0$ ) and the voltage drops. This phenomenon can be modeled as given in Equation 6 by reducing the polarization resistance when the battery is overcharged using the absolute value of it.

$$
\text { Pol.resistance }=\frac{Q}{|i t|-0.1 \cdot Q}
$$

Li-Ion, LiPo battery discharge equation;

$V b=E_{0}-R \cdot i-K \frac{Q}{Q-i t}(i t+i *)+G \operatorname{Exp}(-B \cdot i t)$

Li-Ion, LiPo battery charge equation;

$V b=E_{0}-R \cdot i-K \frac{Q}{i t-0.1 \cdot Q} \cdot i *-K \frac{Q}{Q-i t} \cdot i t+G \operatorname{Exp}(-B \cdot i t)$

\section{ANFIS Design}

The basis of the ANFIS estimation method is TakagiSugeno-Kang fuzzy inference system. In 1993, Jang developed the ANFIS method and used it to model nonlinear functions, identify nonlinear components in a control system, and estimate chaotic time series. In addition, ANFIS method is introduced to the Fuzzy Logic Designer in MATLAB via a User Interface (GUI). The ANFIS presented structure is shown in Figure 4 [22].

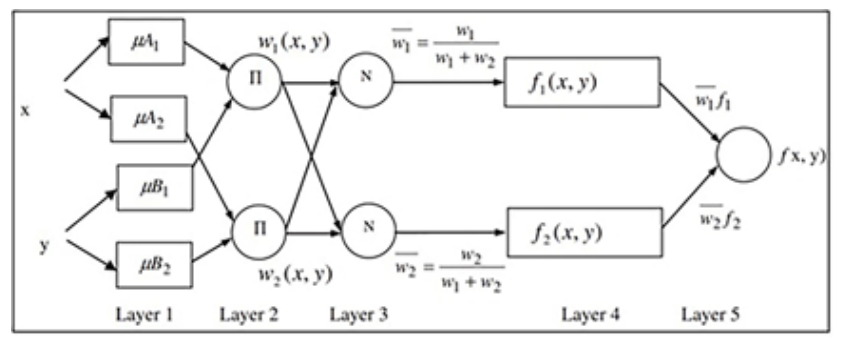

Fig. 4. The structure of ANFIS

In this structure, in the first layer, $\mathrm{Ai}$ and $\mathrm{Bi}$ values are used to express linguistic variables. Each node in this layer 
generates membership grades of the crisp inputs. In the second layer, the inputs are multiplied by each other to form the output of a node. In the third layer, the nodes calculate the ratio of the ith rules firing strength. After the fourth layer, Takagi-Sugeno-Kang model and output variable is defined as a fixed number or polynomial function connected to the variable. [23].

Output function value is calculated with average weight model in TSK Model [24];

$$
x_{o}=\frac{\sum a_{i} \cdot x_{i}}{\sum a_{i}}
$$

In addition, TSK method output values are crisp values. If inference is made by this method, defuzzification is not necessary again. As a result of the fifth layer, the total output value is obtained from the model. The mathematical expression of this process can be summarized as follows;

Set of rules: IF, $\mathrm{x}$ Ai and y Bi then fi=pix+qiy+ri

1. Layer: By selecting a membership function $(\mu(x))$, the degree of membership of the verbal variables is determined. $\left(\mu_{A_{i}}(x), \mu_{B_{i}}(y)\right)$

2. Layer: $\left.w_{i}=\mu_{A_{i}}(x) \cdot \mu_{B_{i}}(y)\right)$

3. Layer: $\overline{w_{l}}=\frac{w_{i}}{\sum w_{i}}$

4. Layer: $\overline{w_{l}} \cdot f_{i}$ the output of the layer.

5. Layer: $x_{o}=\frac{\sum w_{i} f_{i}}{\sum w_{i}}$

\section{Experimental Studies}

\subsection{Battery discharge experiments}

The Panasonic NCR18650 battery cell is modeled using the MATLAB Simulink battery block. An electrical discharge circuit was created in the modeled battery cell and battery discharge was performed on the simulation using constant electrical loads. The simulation results were recorded on the MATLAB workspace and the battery was discharged to a lower voltage of 2.6 volts.

The simulation is terminated when the discharge reaches the battery low limit voltage. The visualization of the model performed on MATLAB Simulink is given in Figure 5. Battery discharge test, charge status-voltage curves are given in Figure 6.

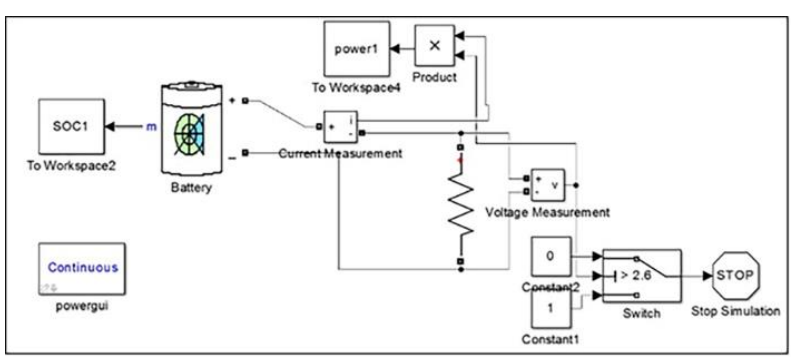

Fig. 5. Discharge circuit model

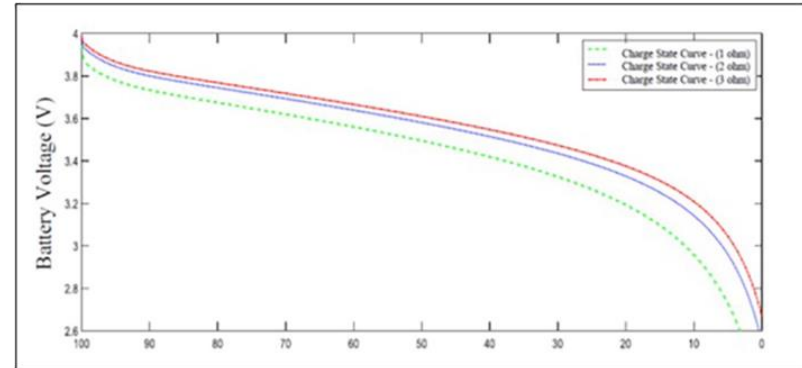

Fig. 6. Battery charge state-voltage curves in different load tests in battery discharge experiment

\subsection{ANFIS application and experimental results}

In MATLAB / Simulink environment, the controller was designed with the help of ANFIS toolbox and trained using experimental data. The input parameters used in the training of the ANFIS neural network are battery voltage, current, temperature and instantaneous power consumption on the battery. If the ANFIS neural network is the target, the battery charge status is an estimate. Gaussmf type function is used in membership functions created for rule base. The limits of the input membership function defined for the battery voltage of the ANFIS neural network before training are given in Figure 7. The new limits for the input membership function defined for battery voltage after training are given in Figure 8 .

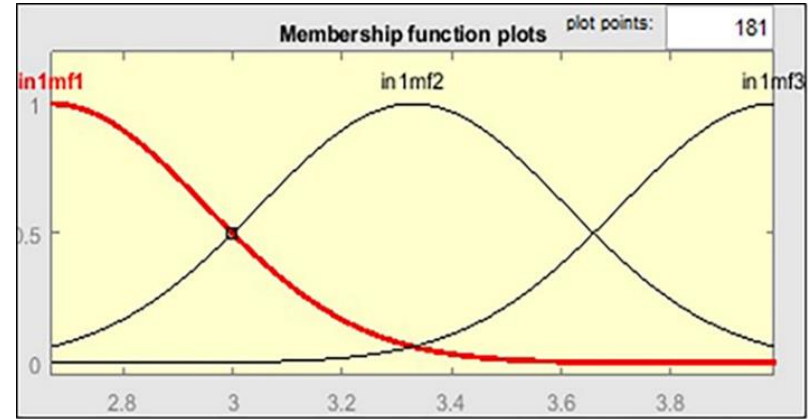

Fig. 7. Limits of pre-training input membership function

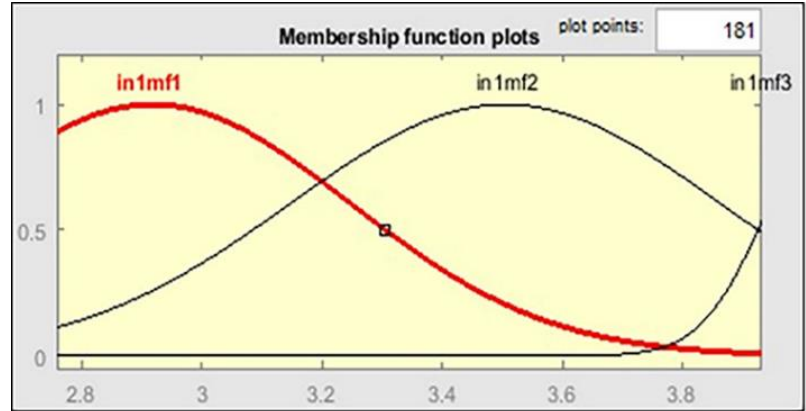

Fig. 8. New boundaries of input membership function after training

A screen shot of the structure of the ANFIS neural network established between the input and output information, which results from the training of the ANFIS neural network, is given in Figure 9.

$80 \%$ of the data obtained from the test circuit is used as training data. The trained ANFIS neural network was then tested using $20 \%$ of the experimental data obtained and estimated the battery charge status. The error-iteration graph of the trained neural network is given in Figure 10 


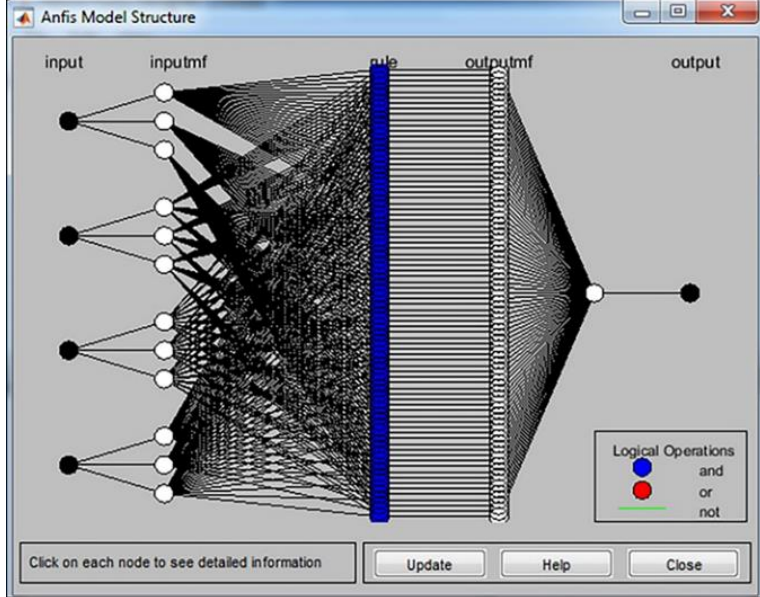

Fig. 9. Structure of ANFIS neural network after training

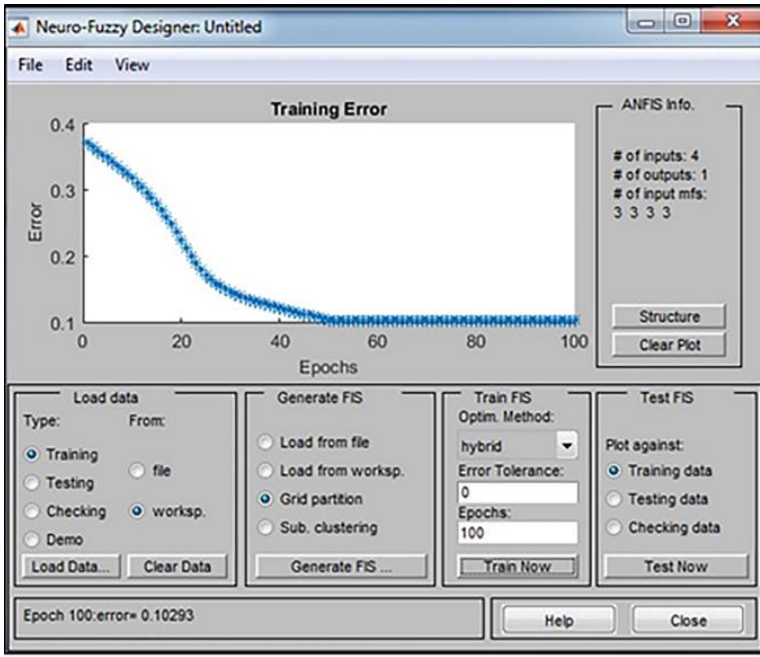

Fig. 10. Error-iteration curve of ANFIS training

\section{Results and Discussions}

In this study, the charge state estimation of a Li-Ion battery cell with adaptive neural fuzzy interest system was performed. The data required for ANFIS training was obtained by creating a battery discharge circuit model modeled on MATLAB Simulink platform. The simulation of the generated battery discharge circuit model was realized by completely discharging the fully charged battery cell using different constant electrical loads. ANFIS was trained with $80 \%$ of the data received and its performance tested with $20 \%$.

The test data related to the battery charge status obtained as a result of discharging the battery under $1 \mathrm{ohm}, 2 \mathrm{ohm}$ and 3 ohm loads and the estimation graph of the charge status data of the ANFIS neural network are given in Figure 11. Figure 12 illustrates the relationship between the training data and the estimation data of the ANFIS neural network.

When the values given in Table 1 are compared, it is seen that ANFIS results are very close to the test data. As a result of the error calculation made by comparing ANFIS results for the same input values with the sample data, the mean error value was found to be 0.13571 .

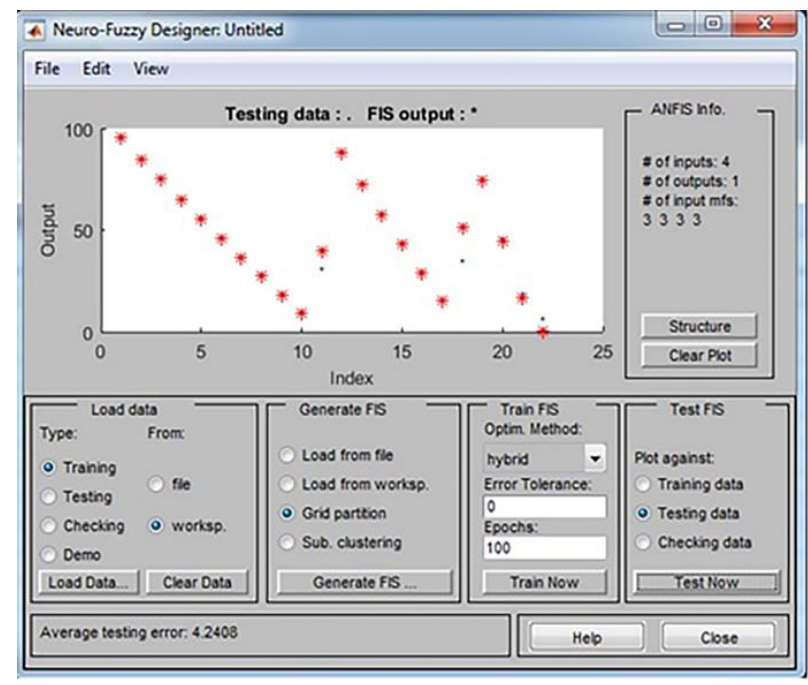

Fig. 11. Battery discharge charge status test data and ANFIS neural network prediction graph

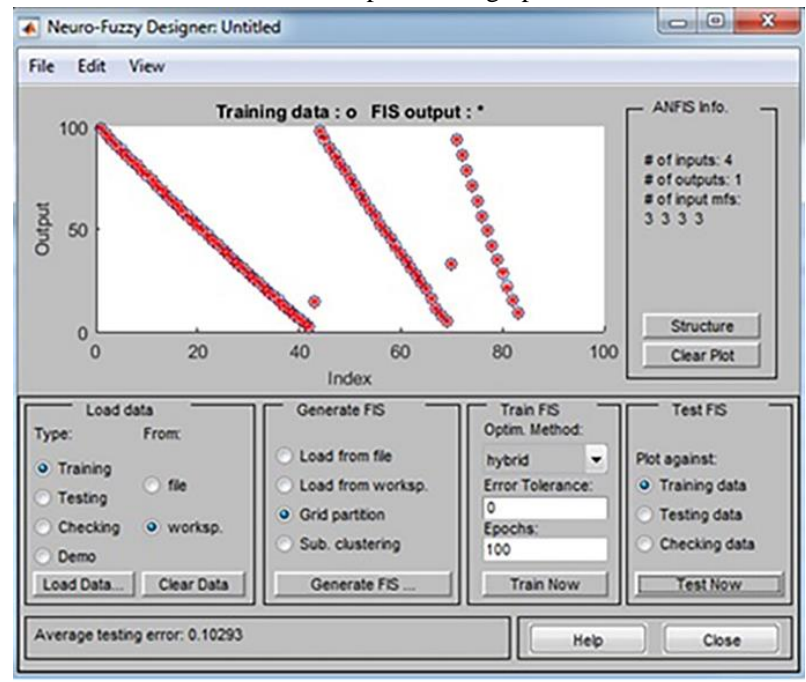

Fig. 12. Battery discharge charge status training data and ANFIS neural network prediction graph

Table 1. Comparison of training data and ANFIS model results

\begin{tabular}{ccccccc}
\hline No & \multicolumn{5}{c}{ Battery Parameters } & Estimation \\
\hline $\mathbf{1}$ & $\begin{array}{c}\text { Voltage } \\
(\mathbf{V})\end{array}$ & $\begin{array}{c}\text { Ampere } \\
(\mathbf{A})\end{array}$ & $\begin{array}{c}\text { Temperature } \\
\left({ }^{\mathbf{0}} \mathbf{C}\right)\end{array}$ & $\begin{array}{c}\text { Power } \\
(\mathbf{W})\end{array}$ & $\begin{array}{c}\text { Battery Charge } \\
\text { Status (\%) }\end{array}$ & $\begin{array}{c}\text { ANFIS Charge } \\
\text { Status (\%) }\end{array}$ \\
\hline $\mathbf{2}$ & 3.93 & 1.31 & 25 & 5.15 & 98.72 & 98.7 \\
$\mathbf{3}$ & 3.81 & 1.27 & 25.01 & 4.85 & 89.07 & 88.7 \\
$\mathbf{4}$ & 3.75 & 1.25 & 25.02 & 4.68 & 76.36 & 75.8 \\
$\mathbf{5}$ & 3.52 & 1.17 & 25.03 & 4.13 & 36 & 36.1 \\
$\mathbf{6}$ & 3.43 & 1.14 & 25.04 & 3.92 & 25.1 & 25.1 \\
$\mathbf{7}$ & 3.3 & 1.1 & 25.04 & 3.63 & 14.6 & 14.5 \\
\hline
\end{tabular}


The accuracy percentage of the ANFIS result obtained from the test data was found to be $99.72 \%$. Considering these results, it is seen that the ANFIS neural network, which was designed as a result, works with high accuracy.

MATLAB can be applied on ANFIS model by modeling different types of batteries on Simulink platform and achieving high rate of successful results. The operation can be tested on data obtained by charging and discharging the battery cell in the real environment. In addition, performance can be increased by increasing the number of data sets in future studies. New findings can be obtained by comparison with other methods in the literature. In case of participation with the battery producing companies, the status of the batteries can be monitored and contributed to the development of the field.

\section{$\underline{\text { ORCID }}$}

Yusuf Karabacak

İlker Ali Özkan

İsmail Sarıtaş

0000-0001-9864-7512

0000-0002-5715-1040

0000-0002-5743-4593

\section{References}

[1] Chen, M., Member, S., Rinc, G. A. 2006. Accurate Electrical Battery Model Capable of Predicting Runtime and I - V Performance. IEEE Transactions On Energy Conversion, 21 (2), 504-511.

[2] Low, W. Y., Aziz, J. A., Idris, N. R. N., Saidur, R. 2013. Electrical model to predict current-voltage behaviours of lithium ferro phosphate batteries using a transient response correction method. Journal of Power Sources, 221, 201-209.

[3] Knauff, M. C., Dafis, C. J., Niebur, D., Kwatny, H. G., Nwankpa, C. O., Metzer, J. 2007. Simulink model for hybrid power system test-bed. IEEE Electric Ship Technologies Symposium ESTS 2007, 421-427.

[4] Plett, G. L. 2004. Extended Kalman filtering for battery management systems of LiPB-based HEV battery packs: Part 1. Background, Journal of Power Sources, 134(2), 252-261.

[5] Grasberger, C., Dolan, D. S., Taufik, T. 2012. Development of an Open-Source High-Performance Battery Management System. North American Power Symposium (NAPS), 1-3.

[6] Kaiser, R. 2007. Optimized battery-management system to improve storage lifetime in renewable energy systems, Journal of Power Sources, 168(1 SPEC. ISS.), $58-65$.

[7] Gotaas, E. and Nettum, A. 2000. Single cell battery management systems (BMS). INTELEC TwentySecond International Telecommunications Energy Conference, 2(36), 695-702.
[8] Jung, D. Y., Lee, B. H., Kim, S. W. 2002. Development of battery management system for nickel-metal hydride batteries in electric vehicle applications. Journal of Power Sources. 109(1), 1-10.

[9] Zhu, W. 2011. "A Smart Battery Management System for Large Format Lithium Ion Cells", Ph.D. thesis, The University of Toledo Graduate Faculty, Toledo, iii-iv.

[10] Wan, X. W. X., Wu, J. W. J., Hu, H. H. H. 2009. The smart Battery management system. International Conference on Test and Measurement ICTM '09., 129132.

[11] Sitterly, M., Member, S., Wang, L. Y., Member, S., Yin, G. G., Wang, C. 2011. Enhanced Identi fi cation of Battery Models for Real-Time Battery Management. IEEE Transactions on Sustainable Energy, 2(3),300308.

[12] Soylu, E., Bayir, R. 2016. Measurement of Electrical Conditions of Rechargeable Batteries, Measurement and Control, 49(2), 72-81.

[13] Özkan, İ.A., Ciniviz, M., Candan, F. 2015. Estimating Engine Performance and Emission Values Using ANFIS. International Journal of Automotive Engineering and Technologies, 4(1), 63-67.

[14] Karabacak, Y., Uysal, A. 2017. "Fuzzy logic controlled brushless direct current motor drive design and application for regenerative braking." 2017 International Artificial Intelligence and Data Processing Symposium (IDAP). IEEE, 1-7.

[15] Karabacak, Y., Uysal, A. 2020. "An Embedded Controller Application with Regenerative Braking for the Electric Vehicle." Elektronika ir Elektrotechnika 26.1: 10-17.

[16] Singh, P., Reisner, D. 2002. Fuzzy logic-based state-ofhealth determination of lead acid batteries. Telecommunications Energy Conference, 2002. INTELEC. 24th Annual International. IEEE, 583- 590.

[17] Huria, T., Ceraolo, M., Gazzarri, J., Jackey, R. 2012. High fidelity electrical model with thermal dependence for characterization and simulation of high power lithium battery cells. 2012 IEEE International Electric Vehicle Conference, 1-8.

[18] Salkind, A. J., Fennie, C., Singh, P., Atwater, T., Reisner, D. E. 1999. Determination of state-of-charge and state-of-health of batteries by fuzzy logic methodology. Journal of Power Sources, 80 (1), 293300.

[19] Marcia, G., A Battery's Guide to Immortality, 2019. https://www.mtu.edu/magazine/research/2019/stories/ battery-immortality/. (08 August 2019).

[20] Tremblay, O., Dessaint, L. A. 2009. Experimental validation of a battery dynamic model for $\mathrm{EV}$ applications. World Electric Vehicle Journal, 3(1), 289-298. 
[21] Cheng, K. W. E., Divakar, B. P., Wu, H., Ding, K., Ho, H. F. 2011. Battery-management system (BMS) and SOC development for electrical vehicles, Vehicular Technology, IEEE Transactions on, 60(1), 76-88.

[22] Jang, J.-S. R. 1993, ANFIS: Adaptive-Network-Based Fuzzy Inference System, IEEE Transactions on Systems Man and Cybernetics, 23(3), 665-685.

[23] Şen, Z. Mühendislikte Bulanık Mantık (Fuzzy) ile Modelleme Prensipleri. Su Vakfi Yayınlarl, İstanbul, 2004.

[24] Cojbasic, Z.V., Nikolic Ć., Cojbasic I.L. 2011. Computationally Intelligent Modelling and Control of Fluidized Bed Combustion Process. Thermal Science, 15,321-338. 